\title{
UTILIZAÇÃO DA MANIPUEIRA COMO HERBICIDA ${ }^{1}$
}

\author{
J. JuIio da Ponte ${ }^{2}$ \\ Erbene Gôes ${ }^{2}$
}

\section{RESUMO}

A manipueira (extrato liquido das raízes de mandioca, Manihot esculenta) foi testada, pela primeira vez, como herbicida. O estudo foi conduzido no município de Caucaia, Estado do Ceará, Brasil, sobre dois tipos de substrato: solo recoberto e não recoberto por britas. Em ambas as áreas, vegetavam 17 diferentes espécies de plantas invasoras. A manipueira foi aplicada três vezes, a intervalos de $24 \mathrm{~h}$, na proporção de 5 $\mathrm{L} / \mathrm{m}^{2}$. O composto mostrou satisfatória ação herbicida, matando $70,58 \%$ das espécies ocorrentes na área experimental, enquanto $17,64 \%$ e $11,76 \%$ das demais plantas comportaram-se, respectivamente, como moderadamente resistentes e resistentes ao tratamento.

Palavras-chave: extrato da mandioca, manipueira, herbicida natural.

\section{RÉSUMÉ}

\section{UTILISATION DE LA "MANIPUEIRA" COMME HERBICIDE}

La "manipueira" (extrait liquide des racines du manioc, Manihot esculenta), sous-produit de la fabrication de la farine de manioc, a été essayée par premiére fois comme un herbicide naturel. L'étude a été conduit dans Caucaia, une municipalité de l'État du Ceará - Brésil, sur deux modalités de substrate: sol recouvert et non recouvert par pierrailles. Dans les deux traitements considerés, ont été developpées 17 espèces

1. Trabalho financiado pela Companhia Energética do Ceará (Coelce).

2. Professor-Emérito e Estagiária de Fitopatologia. Universidade Federal do Ceará, Centro de Ciências Agrárias, C. Postal 12168. 60356-001 Fortaleza, Estado do Ceará, Brasil. E-mail: jjdaponte@ig.com.br 
différentes de plantes envahissantes. Trois applications de manipueira ont été faites, avec des délais de 24 heures, dans la proportion de 5 litres par $\mathrm{m}^{2}$. Le produit a demontré um rôle herbicide três satisfaisant, ayant tué $70,58 \%$ des espéces concurrentes dans l'aire expérimentale; d'autre part, pour les autres espéces, $17,64 \%$ et $11,76 \%$ étaient modérément résistantes ou alors résistantes au traitement, respectivement.

Mots-clé: extrait de manioc, nanipueira, herbicide naturel.

\section{INTRODUCÃO}

A rranipueira (residuo líquido da fabricação da farinha e fécula de mandioca, Manihot esculenta Crantz) já foi seguidamente testada e sempre com ótimos resultados -- como nematicida, inseticida, fungicida e acaricida, conforme está resumido em Cartilha da Manipueira (Ponte, 1999), um compêndio que resenha todas as pesquisas sobre a utilização desse composto como defensivo agricola, projeto em curso na Universidade Federal do Ceará, em Fortaleza,Estado do Ceará, cujo inicio remete à década de setenta (Ponte et al., 1979). Paralelamente ao aludido projeto, demonstrava-se a excelência da manipueira como fertilizante uliar (Aragão \& Ponte, 1995), descoberta que tem respaldo no fato de o composto possuir, em altos teores, todos os macro e micronutrientes requeridos pelas plantas superiores, salvo o molibdênio (Ponte et al., 1997).

Neste trabalho, buscando estender o raio de ação da manipueira como defensivo agrícola, ela é testada, pela primeira vez, como herbicida, pois as observações anteriores foram meramente especulativas ou ocasionais (Fioretto, 1994), carecendo de embasamento científico.

\section{MATERIAL E MÉTODOS}

O experimento teve lugar no município de Caucaia, Estado do Ceará, em área de uma subestação de eletricidade da Companhia Energética do Ceará (Coelce), instituição que, impedida pelos órgãos de preservação ambienta! de continuar usando herbicidas comerciais em suas dependências, patrocinou a execução deste projeto de pesquisa com manipueira. 
O ensaio, realizado no o mês de março de 2001, reuniu dois tratamentos - com e sem aplicação de manipueira, tratamentos A e B (testemunha), respectivamente -, e quatro parcelas experimentais (repetições), sendo duas em solo recoberto por britas e duas em solo descoberto. Cada parcela media $20 \mathrm{~m}^{2}$ (4,0m de largura $\mathrm{x} 5,0 \mathrm{~m}$ de comprimento).

Em todas as parcelas, indistintamente, detectou-se a presença de 17 diferentes espécies de ervas invasoras (Tabela 1). Este levantamento se fez ao ensejo do primeiro dia de aplicação dos tratamentos, quando se recolheu uma amostra de dois exemplares de cada planta, os quais, uma vez acondicionados, separadamente, em sacos de polietilenos, foram levados ao Herbário Prof. Prisco Bezerra, unidade do Centro de Ciências da Universidade Federal do Ceará, onde se procedeu a identificação das espécies.

O tratamento com manipueira consistiu em aplicá-la, com auxílio de um regador manual, uma vez por dia, durante três dias consecutivos, sempre pela manhã, entre $9 \mathrm{~h} 30$ e $10 \mathrm{~h} 00$. Aplicaram-se $100 \mathrm{~L}$ por parcela, o correspondente a uma dosagem de $5 \mathrm{~L} \mathrm{~m}^{-2}$. Nas parcelas-testemunhas, aplicou-se água, na mesma quantidade. Utilizou-se manipueira fresca (extraída no dia anterior), proveniente de um cultivar de mandioca industrial, no caso, o cv. Bujá.

Sete dias após a terceira e última aplicação, fez-se a avaliação final dos resultados, classificando-se as plantas em três categorias, de conformidade com o seu comportamento em relação à manipueira, tomando-se as plantas da testemunha como parâmetros: suscetíveis — plantas que morreram com a aplicação de manipueira; moderadamente suscetiveis (ou tolerantes) - plantas que sobreviveram ao tratamento, embora apresentando sintomas de fitotoxidez (atrofia e crestamento de folhas), e resistentes - plantas não afetadas pelo tratamento, apresentando, quando muito, leves efeitos cloróticos.

\section{RESULTADOS E DISCUSSÃO}

Dentre as 17 espécies invasoras ocorrentes na área experimental, 12 plantas (o correspondente a 70,58\%) não resistiram ao tratamento, 
Tabela 1. Plantas invasoras presentes na área experimental (Subestação Elétrica de Caucaia, Companhia Energética do Ceará / COELCE) e seu comportamento em relação ao tratamento com manipueira (extrato líquido das raízes de mandioca).

\begin{tabular}{|c|c|c|}
\hline \multicolumn{2}{|l|}{ Planta } & \multirow[t]{2}{*}{ Comportamento } \\
\hline Nome Científico & Nome Vulgar & \\
\hline Altemanthera tenella Moq. & Quebra-pedra & \\
\hline Aster chinensis $\mathrm{L}$. & Rainha Margarida & \\
\hline Boerhaavia cocciena Mill. & Pega-pinto & \\
\hline $\begin{array}{l}\text { Cenchrus echinatus L. } \\
\text { Chamaesyce hyssopifolia (L.) Small }\end{array}$ & Carrapicho-de-boi & \\
\hline Chloris gayana Kunth & Capim Rhodes & Suscetiveis \\
\hline Croton sp & Marmeleiro & \\
\hline Cyperus rotundus $\mathrm{L}$. & Capim-junco & \\
\hline Evolvulus argenteus Pursch & Dinheiro-em-penca & \\
\hline Malva silvestris $\mathrm{L}$. & Malva & \\
\hline $\begin{array}{l}\text { Priva echinata Juss. } \\
\text { Schrankia leptocarpa DC }\end{array}$ & $\begin{array}{l}\text { Verbena-encarnada } \\
\text { Malícia-roxa }\end{array}$ & \\
\hline Eragrostis ciliaris Link. & Capim-fino ou grama-fina & Moderadamente \\
\hline Solanum paniculatum L. & Jurubeba & Resistentes \\
\hline Turnera subulata Sm. & Chanana & \\
\hline $\begin{array}{l}\text { Calotropis procera } \mathrm{R} . \mathrm{Br} . \\
\text { Ipomoea asarifolia Roem. \& Schult. }\end{array}$ & $\begin{array}{l}\text { Ciúme ou flor-de-seda } \\
\text { Salsa }\end{array}$ & Resistentes \\
\hline
\end{tabular}

fenecendo totalmente: Alternanthera teneila (quebra-pedra), Aster chinensis (rainha Margarida), Boerhaavia cocccinea (pega-pinto), Cenchrus echinatus (carrapicho-de-boi), Chamaesyce hyssopifolia (ervade-leite), Chloris gayana (capim Rhodes), Croton sp. (marmeleiro), Cyperus rotundus (capim-junco), Evoivulus argenteus (dinheiro-empenca), Malva silvestris (malva), Priva echinata (verbana-encarnada) e Schrankia leptocarpa (malícia-roxa). Três outras espécies, totalizando $17,64 \%$, comportaram-se como moderadamente resistentes, sobrevivendo ao tratamento, embora precariamente, pois apresentavam fortes sintomas de atrofia e crestamento foliar: Eragrostis ciliaris (capim-fino ou grama-fina), Solanum panicuiatum (jurubeba) e Turnera subulata (chanana). Por fim, somente duas espécies $(11,76 \%)$ mostraram-se inteiramente infensas à manipueira, classificando-se, portanto, como resis- 
tentes: Calotropis procera (ciúme ou flor-de-seda) e Ipomoea asarifolia (salsa) (Tabela 1).

Para a Coelce, instituição que custeou a execução do projeto na expectativa de encontrar substituto natural para os herbicidas convencionais (pois impedida de usá-los); esses resultados foram recebidos como bastante satisfatórios, uma vez que o tratamento com manipueira mostrou-se capaz de reduzir substancialmente o mato invasor, onde se abrigam passarinhos, lagartixas e outros animais de pequeno porte que, vez por outra, provocam curtos-circuitos e outros danos em suas subestações elétricas. Aliás, os efeitos herbicidas da manipueira poderiam ter sido ainda mais convincentes, caso não ocorressem chuvas durante o período experimental (choveu por ocasião dos três dias, algumas horas após a aplicação), o que impediu um contato mais prolongado do composto com as plantas tratadas. Presumivelmente, as plantas que se classificaram como moderamente resistentes, teriam se comportado como suscetíveis, caso o tratamento tivesse sido ministrado em época de estio. Por outro lado, quando do uso prático da manipueira como herbicida, será conveniente recomendar-se maior número de aplicações; talvez cinco ou seis fossem o ideal.

Em síntese, a manipueira foi aprovada em seu primeiro teste como herbicida. A propósito, já havia alguma expectativa otimista a respeito, visto que, há alguns anos antes, Fioretto (1994), estudando a viabilidade do aproveitamento da manipueira em fertirrigação, observou que algumas espécies de plantas daninhas haviam fenecido ao contato com a rnanipueira. Ocorreu, neste caso, uma observação ocasional, sem o devido embasamento científico, pois a abordagem da manipueira como herbicida não era a finalidade do mencionado estudo.

\section{CONCLUSÃO}

Pode-se concluir que a manipueira, dentro das condições que prevaleceram neste ensaio, mostrou razoável ação herbicida, fato que recomenda a sua utilização para essa finalidade. 


\section{REFERENCIAS BIBLIOGRÁFICAS}

ARAGÃO, M.L.; J.J. DA PONTE, 1995. O Uso da Manipueira - Extrato Liquido das Raízes de Mandioca - como Adubo Foliar. Ci. Agron., 26(112):45-48.

FIORETTO, R.A., 1994. Uso Direto da Manipueira em Fertirrigação. In: CEREDA, M.P. (ed.). Resíduos da Industrialização da Mandioca no Brasil. São Paulo: Paulicéia, p.11-50.

PONTE, J.J. da, 1999. Cartilha da Manipueira, Uso do Composto como Insumo Agrícola. Fortaleza: SECITECE, 53p.

PONTE, J.J. da; Y.C.A.HOLANDA; M.L. ARAGAO \& J. SILVEIRAFILHO, 1997. Ensaio Preliminar sobre a Utilização da Manipueira (Extrato Líquido das Raízes de Mandioca) como Fertilizante Foliar. Rev. Agricultura, 72(1):63-68.

PONTE, J.J. da; J. TORRES \& A. FRANCO, 1979. Investigação sobre uma Possível Ação Nematicida da Manipueira. Fitopatol. Bras., 4(3):43 1-43 5 . 